\title{
Hopkins Awarded Nemmers Prize
}

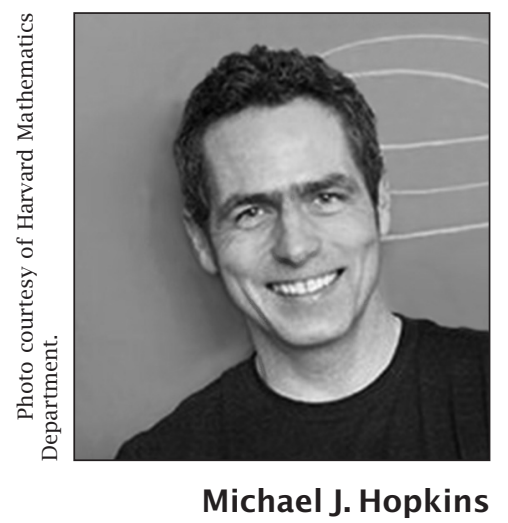

Northwestern University has announced that MiCHAEL J. HOPKINS of Harvard University has been awarded the 2014 Frederic Esser Nemmers Prize in Mathematics. The Nemmers Prize, one of the largest monetary awards in the United States, honors outstanding achievements in mathematics. Awarded to scholars who have made major contributions to new knowledge or to the development of significant new modes of analysis, the prize carries a cash award of US\$200,000.

Hopkins was honored "for his fundamental contributions to algebraic topology, stable homotopy theory, and derived algebraic geometry."

The prize citation reads: "Hopkins's work has revolutionized the field of algebraic topology, a field of mathematics which studies topological or geometric structures using the methods of algebra. He has pioneered the application of homotopy theory to a range of areas in mathematics, collaborating with geometers, number theorists, and mathematical physicists.

"Working with Michael Hill and Douglas Ravenel, Hopkins recently solved the long-standing Kervaire invariant problem. While this question first arose in the 1940s, it has a long history at Northwestern, particularly in the work of Mark Mahowald."

Michael J. Hopkins received his Ph.D. in 1984 from Northwestern University under the direction of Mark Mahowald. Also in 1984 he earned a D.Phil. (doctor of philosophy) in mathematics from the University of Oxford as a result of his work there as a Rhodes Scholar. He held professorships at the Massachusetts Institute of Technology and the University of Chicago before joining Harvard in 2005. His honors include the Oswald Veblen Prize in Geometry of the AMS (2001) and the National Academy of Sciences Award in Mathematics (2012). He is a member of the National Academy of Sciences and the American Academy of Arts and Sciences and a foreign member of the Royal Danish Academy of Sciences and Letters.

In connection with the Nemmers Prize, Hopkins will deliver a public lecture and participate in other scholarly activities at Northwestern during the 2014-2015 and 2015-2016 academic years.

Northwestern University also announced that Jean Tirole of the Toulouse School of Economics was awarded the 2014 Erwin Plein Nemmers Prize in Economics, which also carries a cash prize of US\$200,000.

The Nemmers Prizes are made possible through bequests from the late Erwin E. Nemmers, a former member of the Northwestern University faculty, and his brother, the late Frederic E. Nemmers, both of Milwaukee. The prizes are awarded every other year. Previous Nemmers Prize recipients are Yuri I. Manin (1994), Joseph B. Keller (1996), John H. Conway (1998), Edward Witten (2000), Yakov G. Sinai (2002), Mikhael Gromov (2004), Robert P. Langlands (2006), Simon Donaldon (2008), Terence Tao (2010), and Ingrid Daubechies (2012).

Consistent with the terms of the Nemmers bequests, the Erwin Plein Nemmers Prize in Economics (named in honor of the Nemmers' father) and the Frederic Esser Nemmers Prize in Mathematics (named by Erwin in honor of his brother) are designed to recognize "work of lasting significance" in the respective disciplines. 